\title{
Sorption Kinetic of Arsenate as Water Contaminant on Zero Valent Iron
}

\author{
Osama Eljamal, Keiko Sasaki, Tsuyoshi Hirajima \\ Department of Earth Resources Engineering, Kyushu University, Fukuoka, Japan \\ Email: ommj73@yahoo.com,osama-eljamal@kyudai.jp
}

Received March 5, 2013; revised April 9, 2013; accepted May 3, 2013

Copyright (C) 2013 Osama Eljamal et al. This is an open access article distributed under the Creative Commons Attribution License, which permits unrestricted use, distribution, and reproduction in any medium, provided the original work is properly cited.

\begin{abstract}
This study investigates the sorption of arsenate from water using zero-valent iron ZVI as sorbent. Batch experiments were carried out to study the sorption kinetics of arsenate under different concentrations of arsenate varies from 0.5 to $200 \mathrm{mg} / \mathrm{l}$. A kinetic model was considered to describe the arsenates sorption on ZVI material. The kinetics of the arsenate sorption processes were described by the Langmuir kinetic model. The sorption capacity increases with high initial concentration which obtained the maximum sorption $2.1 \mathrm{mg} / \mathrm{g}$ at $200 \mathrm{mg} / \mathrm{l}$ of arsenate initial concentration. The results show that the rapid initial sorption rates of arsenate were occurred at the beginning of experiments running time, followed by a slower removal that gradually approaches an equilibrium condition. The data from laboratory batch experiments were used to verify the simulation results of the kinetic model resulting in good agreement between measured and modeled results. The results indicate that ZVI could be employed as sorbent materials to enhance the sorption processes and increase the removal rate of arsenate from water.
\end{abstract}

Keywords: Arsenic Sorption; Langmuir Kinetic Model; Zero-Valent Iron; Removal of Arsenate; Iron(III)

\section{Introduction}

Arsenic contamination of drinking water is an issue of great concern. Due to its high toxicity to humans, the World Health Organization (WHO) has set a maximum concentration limit $10 \mu \mathrm{g} / 1$ for arsenic in drinking water [1].

Natural occurrence of arsenic in groundwater is associated with sedimentary deposits, volcanic deposits, geothermal fields, neotectonic active fault areas and regions near lacustrine or marine deposits [2]. A sizeable amount of them also occur due to irresponsible human activity, such as agricultural activities, where arsenic is used for the production of insecticides and herbicides. Areas, which are close to mining activities, have also been found to contain elevated arsenic concentrations.

Arsenic is present mainly in inorganic forms in natural waters. Inorganic arsenic species are predominantly in molecular form of $\mathrm{H}_{3} \mathrm{AsO}_{3}^{0}$ and the negatively charged $\mathrm{H}_{2} \mathrm{AsO}_{4}^{-}$and $\mathrm{HAsO}_{4}^{2-}$ at neutral $\mathrm{pH}$ values. Arsenate $\mathrm{As}(\mathrm{V})$ is the predominant species in oxygenated environments, whereas As(III) species is the predominate arsenic form in reducing environments (Fields et al., 2000). As(III) can be rapidly oxidized to As(V) during the transport of waters and their mixing with shallow oxidized groundwater, rivers or lakes [3].

Several techniques have been proposed for arsenic removal from water. Current technologies include precipitation, coagulation and filtration, reverse osmosis, ion exchange and adsorption. The development of alternative arsenic treatment technologies is required. Zero valent iron (ZVI) has recently gained attention in removing arsenic due to its applicability under different geochemical conditions, operational simplicity and low cost maintenance [4].

Recently, the kinetics of arsenic removal by ZVI and the factors affecting arsenic removal by ZVI have been studied extensively [5-10]. As(V) removal mechanism by ZVI involves the formation of $\mathrm{Fe}(\mathrm{II})$ and $\mathrm{Fe}(\mathrm{III})$ corrosion products onto the surface of iron due to oxidation. In addition, the surface adsorption is the predominant removal process of $\mathrm{As}(\mathrm{V})$ by ZVI $[9,11]$.

$\mathrm{Su}$ and Puls [12] conducted batch studies to evaluate the effectiveness of four ZVI to remove As(III) and $\mathrm{As}(\mathrm{V})$ from water. Their study showed that ZVI is highly effective in removing arsenic from solution and suggests that arsenic forms stronger surface complexes or the complexes migrate into the iron structure with increasing time. 
Farrell et al. [13] investigated electrochemically and spectroscopically the removal of $\mathrm{As}(\mathrm{V})$ by ZVI media. They concluded that As(V) removal by ZVI involves surface complexation only and does not involve reduction to metallic form. These studies clearly show arsenic removal by ZVI is a viable method that should be considered as an alternative drinking water treatment method. Hence, both oxidation forms of arsenic can be treated by this method.

In this paper, we propose a modeling approach that attempts to describe the sorption kinetic rate of arsenate onto ZVI. The Langmuir kinetic equation was used to represent the kinetic model of arsenate sorption onto ZVI. The purpose of the present work is to investigate the efficiency of ZVI under various initial concentrations to remove arsenate. The laboratory batch test studies were conducted to elucidate the mechanisms of arsenate sorption from water by ZVI and to evaluate kinetic parameters of processes that control the arsenate sorption to verify simulation results of the model.

\section{Materials and Methods}

\subsection{Reactive Materials}

The sorbent used in this research was ZVI, which was supplied by Connelly Ltd., Chicago, IL, USA. The leaching test recommended by the environmental ministry of Japan (notification No. 46 of the ministry of environmental, Japan) showed no toxic species above the maximum concentration limit (MCL). The chemical composition and the characteristics of ZVI are summarized in Table 1.

\subsection{Batch Tests}

Batch experiments were designed to investigate the kinetics and efficiency of arsenate removal in different

Table 1. Chemical composition and the characteristics of ZVI.

\begin{tabular}{|c|c|c|c|c|c|}
\hline \multicolumn{6}{|c|}{$\underline{\text { Composition }}$} \\
\hline Species & Content (\%) & Species & Content $(\%)$ & Species & Content $(\%)$ \\
\hline $\mathrm{Fe}$ & 89.82 & $\mathrm{P}$ & 0.132 & Mo & 0.15 \\
\hline $\mathrm{C}$ & 2.85 & $\mathrm{Si}$ & 1.85 & $\mathrm{Ti}$ & 0.004 \\
\hline Mn & 0.6 & $\mathrm{Ni}$ & $0.05-0.21$ & $\mathrm{Cu}$ & $0.15-0.20$ \\
\hline $\mathrm{S}$ & 0.107 & $\mathrm{Cr}$ & $0.03-0.17$ & & \\
\hline \multicolumn{6}{|c|}{ Characteristics } \\
\hline \multicolumn{3}{|c|}{ Parameters } & \multicolumn{3}{|c|}{ Data } \\
\hline \multicolumn{3}{|c|}{ Grain size range } & \multicolumn{3}{|c|}{$0.2-0.25 \mathrm{~mm}$} \\
\hline \multicolumn{3}{|c|}{ Bulk density } & \multicolumn{3}{|c|}{$2.4 \mathrm{~g} \cdot \mathrm{cm}^{-3}$} \\
\hline \multicolumn{3}{|c|}{ Specific surface area } & \multicolumn{3}{|c|}{$1.8 \mathrm{~m}^{2} \cdot \mathrm{g}^{-1}$} \\
\hline \multicolumn{3}{|c|}{ Hydraulic conductivity } & \multicolumn{3}{|c|}{$5 \times 10^{-2} \mathrm{~cm} \cdot \mathrm{s}^{-1}$} \\
\hline
\end{tabular}

initial concentration values $(0.5$ - $200 \mathrm{mg} / \mathrm{l})$. Arsenic solutions were prepared by adding $\mathrm{KH}_{2} \mathrm{AsO}_{4}$ to clean water and the $\mathrm{pH}$ controlled at 9.0 using $\mathrm{HCl}$ solution during the tests.

The ZVI was washed with ethanol and acetone to remove the dust layer on ZVI.

Five grams of ZVI was added into $0.25 \mathrm{~L}$ of prepared solution in a glass flask. The solution in a flask had been purged with nitrogen gas for about $30 \mathrm{~min}$. The mixtures were shaken at $100 \mathrm{rpm}$ and $25^{\circ} \mathrm{C}$ for $100 \mathrm{~h}$. At different periods solution samples were taken and filtered with a $0.2 \mathrm{~mm}$ membrane filter prior to determination of $\mathrm{As}(\mathrm{V})$ by LC-ICP-MS (Agilent 7500CE, YOKOGAWA, Japan).

\section{Results and Discussion}

\subsection{Kinetics of the Arsenates Uptake}

For the parameters evaluation of the sorption process the most important physicochemical aspects are the kinetics and equilibrium of sorption. The $\mathrm{As}(\mathrm{V})$ solid concentrations and $\mathrm{As}(\mathrm{V})$ removal kinetics at various initial concentrations, with the ZVI is shown in Figures 1-8. The results indicate that the rate of sorption is very fast initially and reaches a plateau at equilibrium time within 20 $\mathrm{h}$. while the high removal percentage is $55 \%$ occurred at the first 3 hours. The results show that the rate of decrease of arsenic from the solution is dependent on the initial arsenate concentration (highest rate for highest concentration and lower rates for the lower concentrations). Because of such a quick sorption rate, it can be obtained that the diffusion in this case is predominantly film diffusion mechanism, which is effected by the differences in concentration between the solution and ZVI surface area. The sorption kinetic of arsenate model describes the rate at which chemical reactions occur in $\mathrm{As} / \mathrm{ZVI} / \mathrm{H}_{2} \mathrm{O}$ system. The Langmuir equation is widely used for sorption

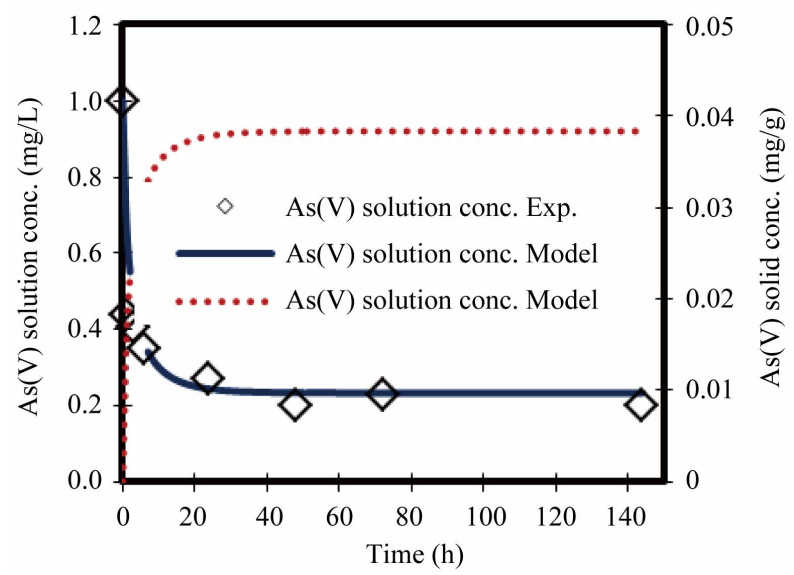

Figure 1. Change in arsenate concentration in solution and solid versus time. Initial conc. of arsenate $1 \mathrm{mg} / \mathrm{L}$. 


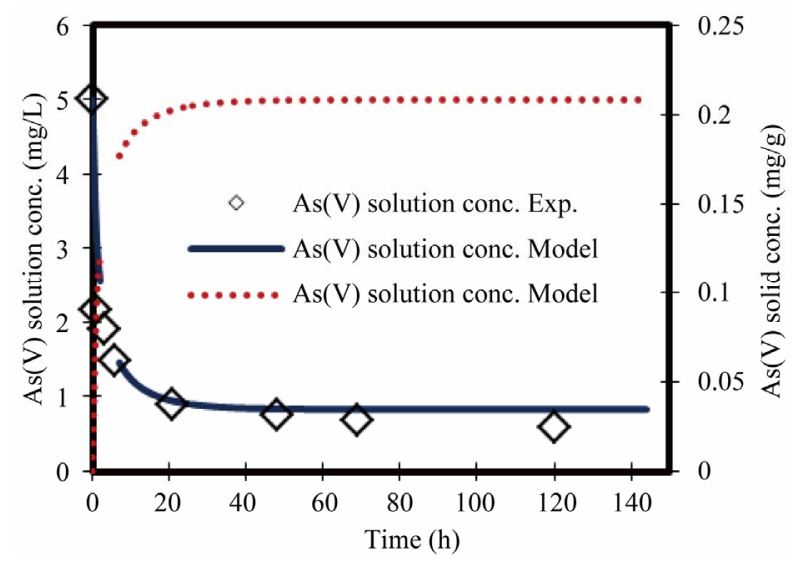

Figure 2. Change in arsenate concentration of solution and solid versus time. Initial conc. of arsenate $5 \mathrm{mg} / \mathrm{L}$.

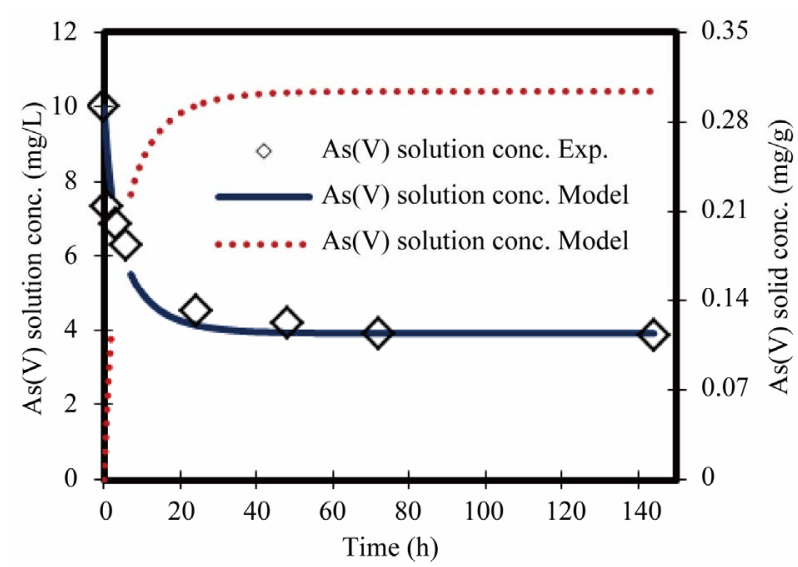

Figure 3. Change in arsenate concentration in solution and solid versus time. Initial conc. of arsenate $10 \mathrm{mg} / \mathrm{L}$.

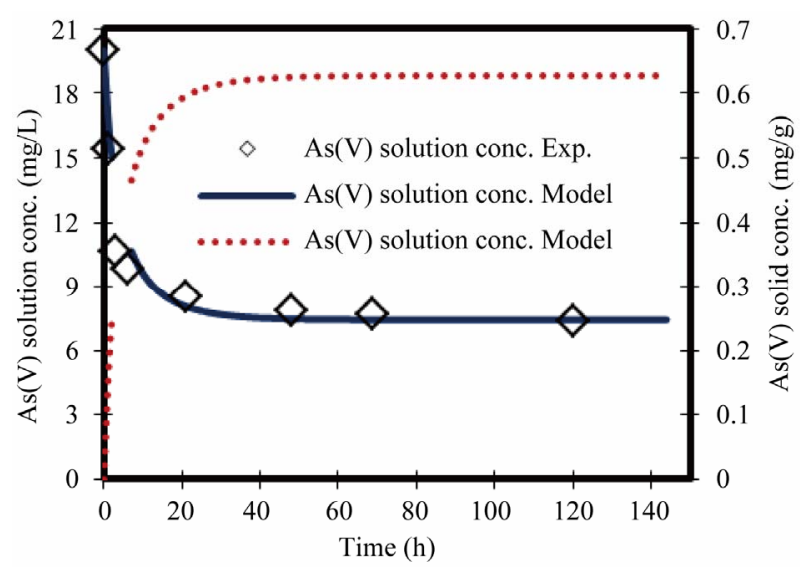

Figure 4. Change in arsenate concentration in solution and solid versus time. Initial conc. of arsenate $20 \mathrm{mg} / \mathrm{L}$.

equilibrium because of its thermodynamical basis. The Langmuir kinetic model assumes monolayer coverage of adsorbate over a homogeneous adsorbent surface, and at equilibrium, a saturation point is reached where no further sorption can occur. The model is represented by the

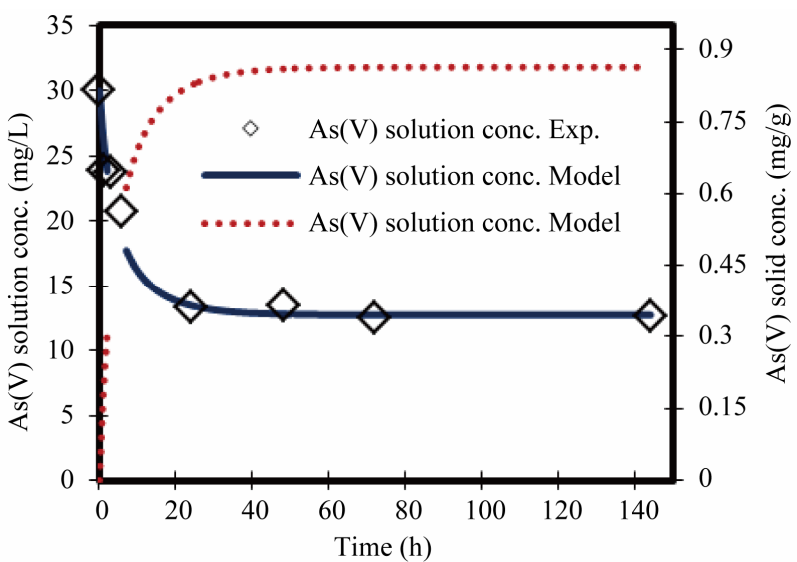

Figure 5. Change in arsenate concentration in solution and solid versus time. Initial conc. of arsenate $30 \mathrm{mg} / \mathrm{L}$.

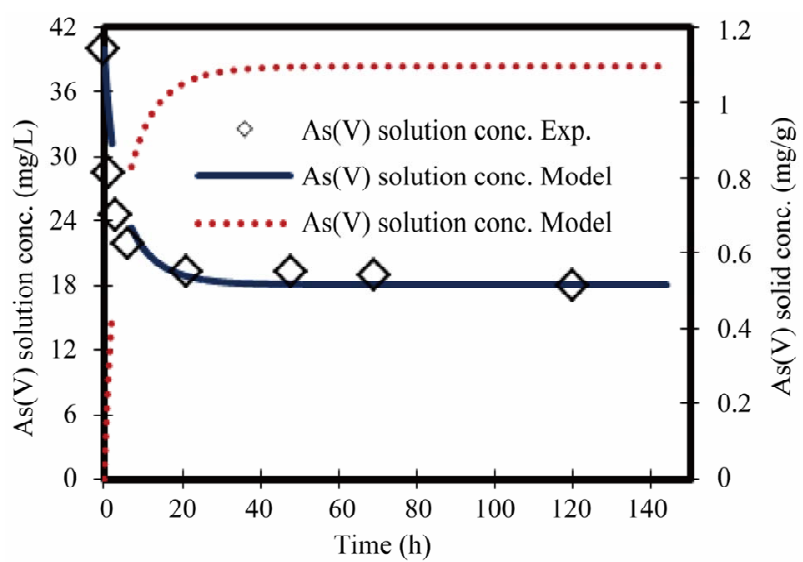

Figure 6. Change in arsenate concentration in solution and solid versus time. Initial conc. of arsenate $40 \mathrm{mg} / \mathrm{L}$.

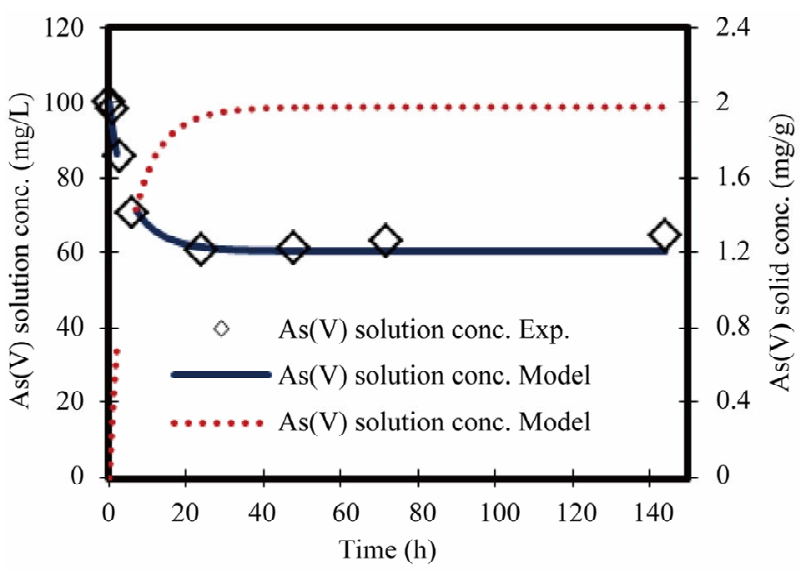

Figure 7. Change in arsenate concentration in solution and solid versus time. Initial conc. of arsenate $100 \mathrm{mg} / \mathrm{L}$.

Langmuir equation and it can be written as follow [14]:

$$
\frac{\mathrm{d} Q}{\mathrm{~d} t}=\frac{\theta}{\rho} K_{1} C\left(Q_{\max }-Q\right)-K_{-1} Q
$$

where $Q$ is the solid concentration ( $\mathrm{mg} / \mathrm{g}), t$ is the time(s), 


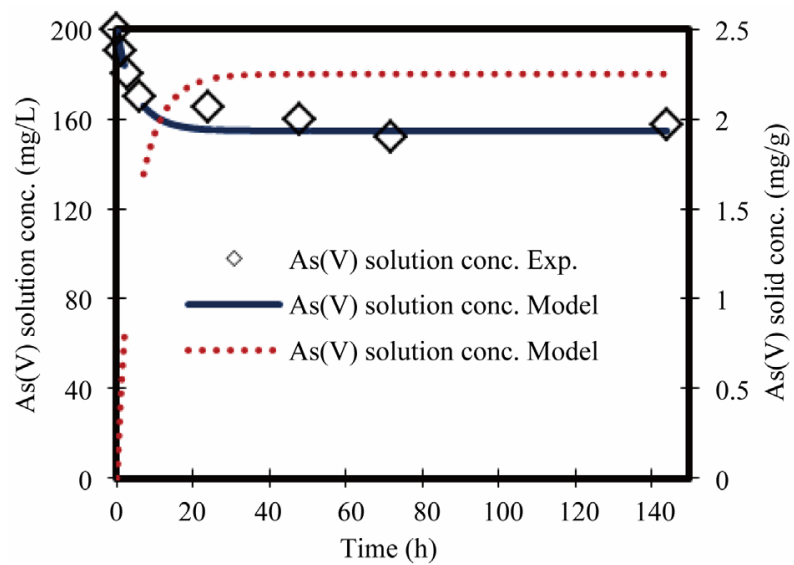

Figure 8. Change in arsenate concentration in solution and solid versus time. Initial conc. of arsenate $200 \mathrm{mg} / \mathrm{L}$.

$\theta$ is the volumetric water content (1), $\rho$ is the bulk density $(\mathrm{g} / \mathrm{l}), K_{1}$ is the Langmuir sorption rate constant $(1 / \mathrm{mg}), C$ is the aqueous concentration $(\mathrm{mg} / \mathrm{l}), Q_{\max }$ is the maximum adsorption capacity $(\mathrm{mg} / \mathrm{g})$ and $K_{-1}$ is the Langmuir dissolution rate constant $(1 / \mathrm{mg})$. It was found that, Langmuir equation provided a good description of the current data. Langmuir parameters of rate constant and maximum adsorption capacity variation with initial concentrations are presented in Table 2.

\subsection{Sorption Isotherms}

In order to investigate the isotherm of solute sorption onto the ZVI, the kinetic model of Langmuir based on solid capacity, was used to analyze the experimental data. The sorption isotherm of $\mathrm{As}(\mathrm{V})$ onto ZVI is shown in Figure 9. The Langmuir equation [14] was fit to the data:

$$
m_{\text {ads }}=0.126 m_{\text {sol }} /\left(1+0.06 m_{\text {sol }}\right)
$$

where $m_{a d s}$ is the sorbed arsenic concentration $(\mathrm{mg} / \mathrm{g})$ and $m_{\text {sol }}$ is the solution arsenic concentration $(\mathrm{mg} / \mathrm{l})$ at equilibrium. The calculated maximum sorption $\left(m_{a d s}\right)$ was 2.1 mg-As/g-ZVI.

The As 3d in the XP spectrum for the residual ZVI after $48 \mathrm{~h}$ contacting with $\mathrm{As}(\mathrm{V})$ is shown in Figure 10. The spectrum was separated into two components, with $\mathrm{As}(\mathrm{V})$ and $\mathrm{As}(\mathrm{III})$ at $45.09 \mathrm{eV}$ and $43.82 \mathrm{eV}$ in $\mathrm{EB}[\mathrm{As}$ $3 \mathrm{~d}]$ respectively. The predominant species was $\mathrm{As}(\mathrm{V})$. It was confirmed that arsenate was not reduced to arsenite by ZVI and that arsenate was sorbed onto ZVI.

\subsection{Sorption Mechanism}

The mechanism of arsenate removal by ZVI is rather complex since different processes are involved. It is generally accepted that arsenate uptake from aqueous systems is based on adsorption and co-precipitation phenomena coupled with the continuous dissolution of iron oxyhydroxides. Dzombak and Morel [15] reported that
Table 2. Rate constant and maximum adsorption capacity variation with initial concentrations.

\begin{tabular}{cccc}
\hline $\begin{array}{c}\text { Initial } \\
\begin{array}{c}\text { concentration } \\
\text { of As(V) } \\
(\mathrm{mg} / \mathrm{l})\end{array}\end{array}$ & $\begin{array}{c}\text { Maximum } \\
\text { adsorption } \\
\text { capacity } Q_{\max } \\
(\mathrm{mg} / \mathrm{g})\end{array}$ & $\begin{array}{c}\text { Langmuir } \\
\text { sorption rate } \\
\text { constant, } K_{1} \\
(\mathrm{l} / \mathrm{mg})\end{array}$ & $\begin{array}{c}\text { Langmuir } \\
\text { dissolution rate } \\
\text { constant, } K_{-1} \\
(1 / \mathrm{mg})\end{array}$ \\
\hline 0.5 & 0.023 & 0.8 & 0.0 \\
1.0 & 0.04 & 0.4 & 0.004 \\
5.0 & 0.221 & 0.08 & 0.004 \\
10.0 & 0.308 & 0.023 & 0.00115 \\
20.0 & 0.632 & 0.012 & 0.0006 \\
30.0 & 0.867 & 0.007 & 0.00035 \\
40.0 & 1.101 & 0.006 & 0.0003 \\
100.0 & 1.978 & 0.002 & 0.0001 \\
200.0 & 2.254 & 0.001 & 0.00005 \\
\hline
\end{tabular}

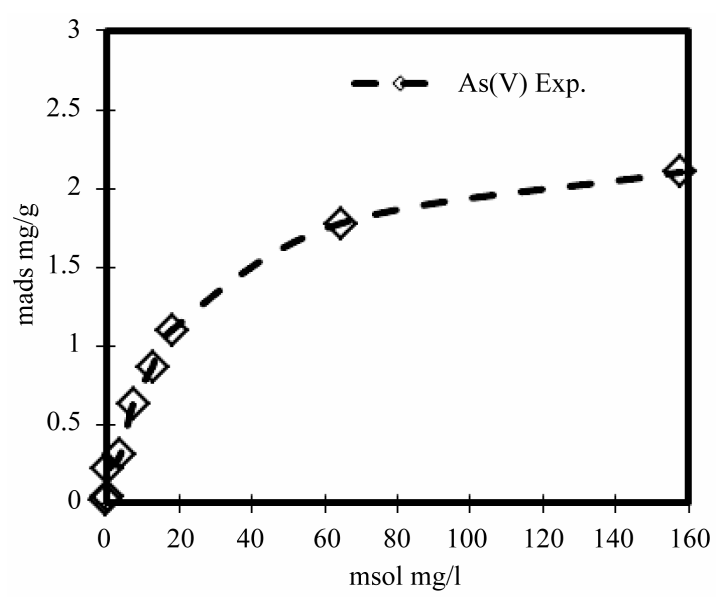

Figure 9. Sorption isotherm of arsenate onto ZVI.

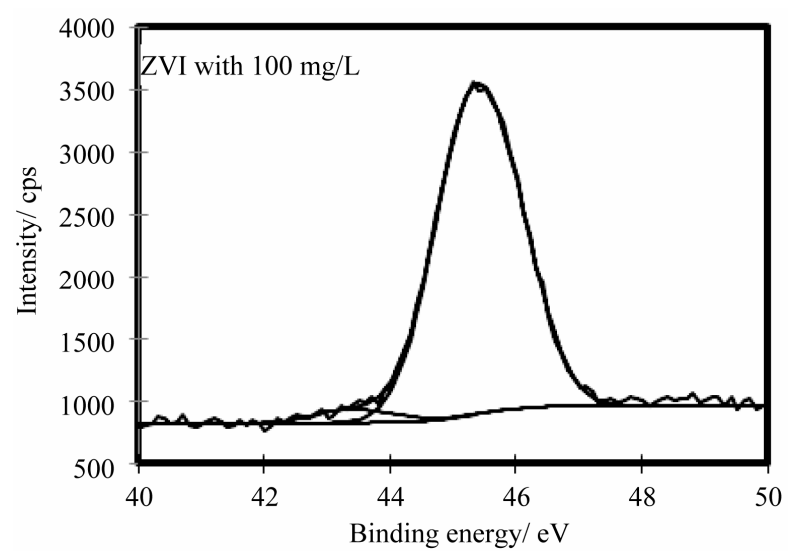

Figure 10. XP spectra of As 3d for residual ZVI after $48 \mathrm{~h}$ contacting with arsenate.

the adsorption of arsenic occurs through the formation of surface complexes with iron. In this case among the two forces, the electrostatic force and chemisorption force, that play a major role in the adsorption processes, chemi- 
sorption is responsible for the $\mathrm{As}(\mathrm{V})$ uptake from water. The adsorption kinetics follows the Langmuir model, which is based on the assumption that the adsorption is mainly chemisorption involving exchange of electrons between sorbate and sorbent [16]. The empty d-orbitals of ferric oxide allow for the complexing of arsenate through oxidation or replacement of the hydroxyl group [17]. The possible reaction of $\mathrm{As}(\mathrm{V})$ with the hydrated ferric oxide can be written as follow:

$$
\mathrm{HAsO}_{4}^{2-}+\mathrm{Fe}-\mathrm{OH}+\mathrm{H}^{+}=\mathrm{FeHAsO}_{4}^{-}+\mathrm{H}_{2} \mathrm{O}
$$

\section{Conclusions}

In this paper, we propose a modeling approach that attempts to describe the sorption kinetic rate of arsenate onto ZVI. The kinetic rate is well described by Langmuir kinetic model. Feasibility and applicability of parameters were assessed by conducting a laboratory batch experiments and comparing the simulated results with the experimental data.

In this study, ZVI was found out to be effective sorbent for the removal of arsenate form water. The results showed that ZVI has a high potential for sorption of arsenate from water.

Investigations on the mechanism of $\mathrm{As}(\mathrm{V})$ sorption onto the sorbent (ZVI) indicated that the experimental data followed the Langmuir kinetics over the whole concentration range, which also indicated that the chemical adsorption played a major role in the As(V) uptake.

The results of this study could be used for designing and developing a model of permeable reactive barriers (PRBs) where the removal of arsenic by ZVI is a very important step in production of drinking water from ground or surface water.

\section{REFERENCES}

[1] WHO, "Guidelines for Drinking-Water Quality. Vol. 1: Recommendations," 2nd Edition, WHO, Geneva, 1993.

[2] K. Fields, A. Chen and L. Wang, "Arsenic Removal from Drinking Water by Iron Removal Plants," 2000.

[3] F. W. Pontius, G. K. Brown and J. C. Chien, "Health Implications of Arsenic in drinking Water," Journal of American Water Works Association, Vol. 86, No. 9, 1994, pp. 52-63.

[4] H. H. Cho and J. W. Park, "Sorption and Reduction of Tetrachloroethylene with Zero Valent Iron and Amphiphilic Molecules," Chemosphere, Vol. 64, No. 6, 2006, pp. 1047-1052. doi:10.1016/j.chemosphere.2005.12.062

[5] I. Kouznetsova, P. Bayer, M. Ebert and M. Finkel, "Modelling the Long-Term Performance of Zero-Valent Iron Using a Spatio-Temporal Approach for Iron Aging," Journal of Contaminant Hydrology, Vol. 90, No. 1-2, 2007, pp. 58-80. doi:10.1016/j.jconhyd.2006.09.014

[6] Y. T. Lin, C. H. Weng and F. Y. Chen, "Effective Removal of AB24 Dye by Nano/Micro-Size Zero-Valent Iron," Separation and Purification Technology, Vol. 64, No. 1, 2008, pp. 26-30. doi:10.1016/j.seppur.2008.08.012

[7] Y. Mu, H. Q. Yu, J. C. Zheng, S. J. Zhang and G. P. Sheng, "Reductive Degradation of Nitrobenzene in Aqueous Solution by Zero-Valent Iron," Chemosphere, Vol. 54, No. 7, 2004, pp. 789-794. doi:10.1016/j.chemosphere.2003.10.023

[8] S. Bang, M. D. Johnson, G. P. Korfiatis and X. Meng, "Chemical Reactions between Arsenic and Zero-Valent Iron in Water," Water Research, Vol. 39, No. 5, 2005, pp. 763770. doi:10.1016/j.watres.2004.12.022

[9] N. P. Nikolaidis, G. M. Dobbs and J. A. Lackovic, "Arsenic Removal by Zero-Valent Iron: Field, Laboratory and Modeling Studies," Water Research, Vol. 37, No. 6, 2003, pp. 1417-1425. doi:10.1016/S0043-1354(02)00483-9

[10] J. M. Triszcz, A. Porta and F. G. Einschlag, "Effect of Operating Conditions on Iron Corrosion Rates in Zero-Valent Iron Systems for Arsenic Removal," Chemical Engineering Journal, Vol. 150, No. 2-3, 2009, pp. 431-439. doi:10.1016/j.cej.2009.01.029

[11] R. B. Johnston and P. C. Singer, "Redox Reactions in the FeAs- $\mathrm{O}_{2}$ System," Chemosphere, Vol. 69, No. 4, 2007, pp. 517-525. doi:10.1016/j.chemosphere.2007.03.036

[12] C. Su and R. Puls, "Arsenate and Arsenite Removal by Zero Valent Iron: Kinetics, Redox Transformation and Implications for in Situ Groundwater Remediation," Environmental Science and Technology, Vol. 35, No. 7, 2001, pp. 1487-1492. doi:10.1021/es001607i

[13] J. Farrell, J. Wang, P. O’Day and M. Conklin, “Electrochemical and Spectroscopy Study of Arsenate Removal from Water Using Zero Valent Iron Media," Environmental Science and Technology, Vol. 35, No. 10, 2001, pp. 20262032. doi:10.1021/es0016710

[14] G. Limousin, J. P. Gaudet, L. Charlet, S. Szenknect, V. Barthe's and M. Krimissa, "Sorption Isotherms: A Review on Physical Bases, Modeling and Measurement," Applied Geochemistry, Vol. 22, No. 2, 2007, pp. 249-275. doi:10.1016/j.apgeochem.2006.09.010

[15] D. A. Dzombak and F. M. M. Morel, "Surface Complexation Modelling: Hydrous Ferric Oxide," Wiley-Interscience, New York, 1990.

[16] T. H. Hsia, S. L. Loa, C. F. Lin and D. Y. Lee, "Characterization of Arsenate Adsorption on Hydrous Iron Oxide Using Chemical and Physical Methods," Colloids and Surfaces A: Physicochemical and Engineering Aspects, Vol. 85, No. 1, 1994, pp. 1-7. doi:10.1016/0927-7757(94)02752-8

[17] B. E. Reed, R. Vaughan and L. Jiang, “As(III), As(V), Hg and $\mathrm{Pb}$ Removal by Fe-Oxideimpregnated Activated Carbon," Journal of Environmental Engineering, Vol. 126, No. 9, 2000, pp. 869-873. doi:10.1061/(ASCE)0733-9372(2000)126:9(869) 